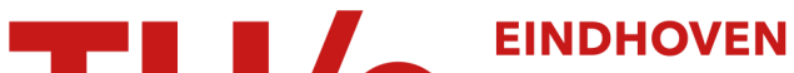 \\ UNIVERSITY OF \\ TECHNOLOGY
}

\section{Photoamperic probes in scanning tunneling microscopy}

\section{Citation for published version (APA):}

Prins, M. W. J., Wielen, van der, M. C. M. M., Jansen, R., Abraham, D. L., \& Kempen, van, H. (1994). Photoamperic probes in scanning tunneling microscopy. Applied Physics Letters, 64(10), 1207-1209. https://doi.org/10.1063/1.110891

DOI:

10.1063/1.110891

Document status and date:

Published: 01/01/1994

\section{Document Version:}

Publisher's PDF, also known as Version of Record (includes final page, issue and volume numbers)

\section{Please check the document version of this publication:}

- A submitted manuscript is the version of the article upon submission and before peer-review. There can be important differences between the submitted version and the official published version of record. People interested in the research are advised to contact the author for the final version of the publication, or visit the $\mathrm{DOI}$ to the publisher's website.

- The final author version and the galley proof are versions of the publication after peer review.

- The final published version features the final layout of the paper including the volume, issue and page numbers.

Link to publication

\section{General rights}

Copyright and moral rights for the publications made accessible in the public portal are retained by the authors and/or other copyright owners and it is a condition of accessing publications that users recognise and abide by the legal requirements associated with these rights.

- Users may download and print one copy of any publication from the public portal for the purpose of private study or research.

- You may not further distribute the material or use it for any profit-making activity or commercial gain

- You may freely distribute the URL identifying the publication in the public portal.

If the publication is distributed under the terms of Article 25fa of the Dutch Copyright Act, indicated by the "Taverne" license above, please follow below link for the End User Agreement:

www.tue.nl/taverne

Take down policy

If you believe that this document breaches copyright please contact us at:

openaccess@tue.nl

providing details and we will investigate your claim. 


\title{
Photoamperic probes in scanning tunneling microscopy
}

\author{
M. W. J. Prins, M. C. M. M. van der Wielen, R. Jansen, D. L. Abraham, and H. van Kempen \\ Research Institute for Materials, University of Nijmegen, Toernooiveld, $N L-6525$ ED Nijmegen, \\ The Netherlands
}

(Received 5 October 1993; accepted for publication 8 December 1993)

\begin{abstract}
The charge generated at the apex of a semiconductor tip upon laser irradiation is utilized in a scanning tunneling microscope. We show such arrangements can produce photoinduced tunnel currents of several hundred picoamperes, sufficient for stable STM operation and sensitive enough to detect nanowatt variations in the incident optical power.
\end{abstract}

Among the variety of emergent scanned probe microscopies, those exploiting optical interactions near the probe tip hold a special attraction with regard to deriving local spectroscopic and material information. In the special case of semiconductor surfaces, incident radiation will often produce charge accumulation giving rise to a surface photovoltage (SPV) which may be detected by suitable potentiometric methods. ${ }^{1}$ Using a scanning tunneling microscope (STM), the local SPV at selected surfaces has been investigated, most notably Si surfaces, ${ }^{2,3}$ III-V materials and nanostructures, ${ }^{4,5}$ and $\mathrm{WSe}_{2} .{ }^{6}$ While there are questions concerning the influence of the STM junction on the local surface potential, ${ }^{7,8}$ the general picture emerging from these studies is one in which the SPV is sensitive to surface electronic structure as well as local surface and bulk transport properties. Until recently however, little attention has been given to the photoinduced tunnel current derivable at the STM junction.

Under steady-state photoexcitation, the SPV represents a balance of photogenerated minority carrier flux toward the surface with the internal (majority carrier) restoring current. ${ }^{1}$ The photogenerated flux is predominantly a bulk process determined by transport lengths associated with drift in the surface depletion field and bulk diffusion, relative to the optical penetration depth. ${ }^{9}$ In our STM pumping configuration it is not unusual to generate minority carrier current densities of order $1 \mathrm{~A} \mathrm{~cm}^{-2}$ which is minute compared to typical STM current densities of order $10^{5} \mathrm{~A} \mathrm{~cm}^{-2}$. Nevertheless, photoinduced tunnel currents around $100 \mathrm{pA}$ have already been extracted from III-V semiconductors using rather modest light intensities. ${ }^{4,10}$ Evidently, significant lateral transport must occur in response to the intrusive local current density established by the STM junction. In light of these considerations, we are led to explore the properties of a semiconductor STM tip in an optical pumping arrangement. The following experiments show that semiconductor STM tips may produce photoinduced tunnel currents in the nanoampere range in response to incident optical intensities less than 1 $\mathrm{mW} / \mathrm{mm}^{2}$. Moreover, we demonstrate photoamperic operation where now the tunnel current is proportional to the incident optical intensity, with conversion efficiencies comparable to macroscopic photodetectors.

The measurements were carried out in ambient conditions with a STM having provision for optical pumping from the side of the tip, at about $50^{\circ}$ from the sample normal, and along the tip axis through a semitransparent sample. In all of these tests a $10 \mathrm{~mW}$ HeNe laser $(633 \mathrm{~nm})$ was followed by a pair of polarizers for intensity adjustment, a Pockels cell, removable polarizer, chopper, and finally a $30 \mathrm{~mm}$ focal length objective. The spot size at the tip was nominally 40 $\mu \mathrm{m}$ and the incident power ranged from a few $\mathrm{mW}$ to less than $1 \mu \mathrm{W}$.

Before considering the photoresponse of semiconductor STM tips, we carried out an extensive set of photoassisted tunneling measurements on cleaved $\operatorname{GaAs}(110)$ faces to determine the magnitude of such currents for a range of dopant densities ( $p$-type ranging from $10^{16} \mathrm{~cm}^{-3}$ to $10^{19} \mathrm{~cm}^{-3}$ ), light intensity and tip-sample distance. ${ }^{11}$ Subsequently, a variety of semiconductor tips were tested: $\mathrm{Si}\left(p-10^{17} \mathrm{~cm}^{-3}\right)$, GaAs $\left(p-10^{17} \mathrm{~cm}^{-3}, p-10^{19} \mathrm{~cm}^{-3}\right.$, and $\left.n-10^{17} \mathrm{~cm}^{-3}\right)$. The Si tips were prepared by breaking a (111) oriented wafer to form a shard then dipping in buffered HF solution. The GaAs tips were prepared by cleaving (001) wafers along (110) directions, forming a corner bounded by these planes. Inspection by SEM indeed showed the cleaves produced well defined corners rather than protruding microtips.

The photoassisted tunneling measurements shown here consist of open-loop static current-voltage $(I-V)$ characteristics at different incident light intensities and set point values for current and voltage. Any influence of open-loop thermal drift on measured curves could be excluded by ramping the voltage both up and down over the same interval. Varying the setpoint values or equivalently the tunnel conductance will change the tip-sample preparation, showing at least relative behavior since the absolute distance is not determined here. The photovoltage $\left(V_{p}\right)$ is determined by the current null, provided the differential conductivity is not too low $\left[(d I / d V)^{-1}<10^{11} \Omega\right]$. The photoinduced current $\left(I_{0}\right)$ is taken at the point of zero applied bias. Accurate determination of $I_{0}$ as a function of light intensity at constant tipsample separation was accomplished by means of a light intensity ramp during the loop-hold period.

Figure 1 shows a family of characteristics for a cleaved GaAs $(110)$ surface $\left(p-10^{17} \mathrm{~cm}^{-3}\right)$ where the setpoint is varied, maintaining constant light intensity. The salient features upon illumination are (i) constant $V_{p}$ of $400 \mathrm{mV}$ and (ii) large variations in $I_{0}$. The inset shows characteristics with (broken) and without (solid) $300 \mu \mathrm{W}$ incident power at the same tip-surface separation, showing that indeed the dramatic change in rectifying behavior is due to photoexcitation rather than tip-surface contact or heating effects. The striking feature here is the rapid increase of $I_{0}$ as the tip is brought 


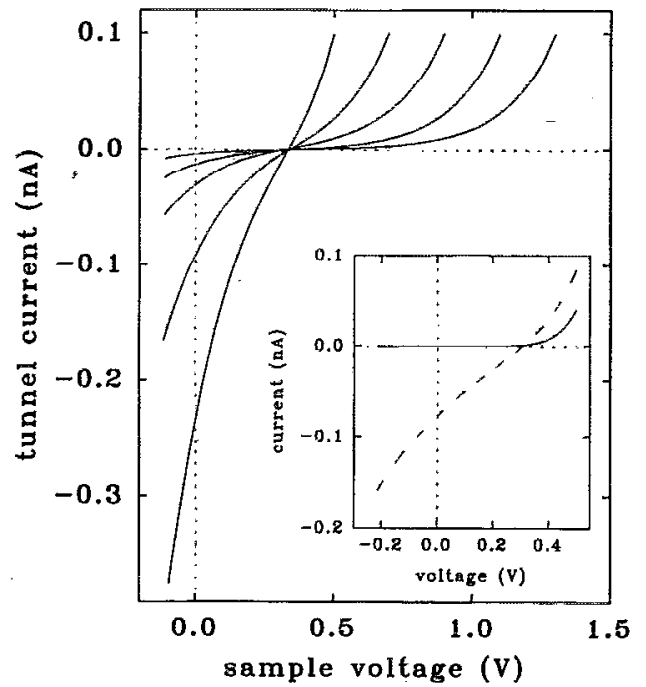

FIG. 1. Current-voltage characteristics for GaAs(110) surface and PtIr tip under constant laser excitation. The inset shows characteristics with (broken) and without (solid) laser excitation $(300 \mu \mathrm{W})$ at the same tip-surface separation.

closer to the surface, indicating the photoassisted contribution is limited by the tunncl junction more than transport in the semiconductor. Similar to previous studies, ${ }^{7}$ we also observe a logarithmic dependence of $V_{p}$ on light intensity. ${ }^{11}$

The characteristics for a representative semiconductor STM tip are shown in Fig. 2, obtained on a semitransparent Au film. The tip is a cleaved GaAs corner $\left(n-10^{17} \mathrm{~cm}^{-3}\right)$ with photoexcitation made along the tip axis. Figure 2(a) shows a family of curves without illumination and serves as a reference for tip behavior. Figure 2(b) shows characteristics with an input power of $1 \mu \mathrm{W}$, producing a $V_{p}$ of about 250

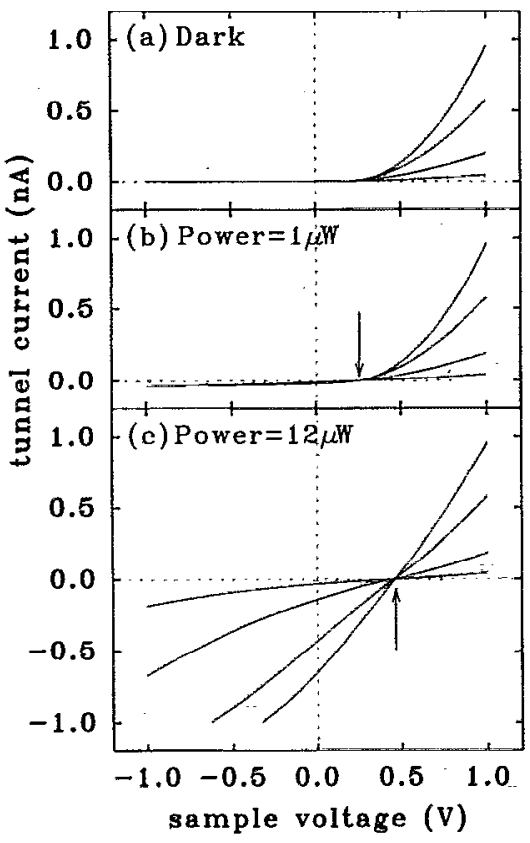

FIG. 2. Current-voltage characteristics for a cleaved GaAs tip and semitransparent Au sample, with laser excitation along the tip axis.

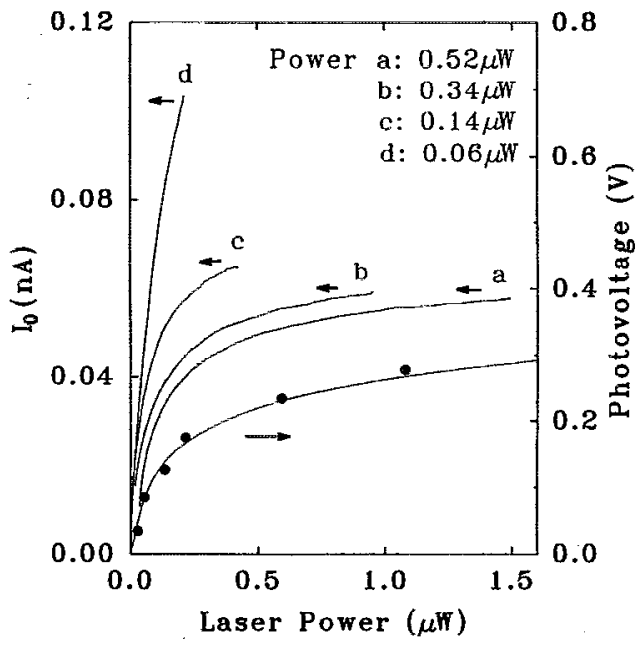

FIG. 3. Tip photovoltage (filled circles) and zero-bias current (a, b, c, and d) as a function of incident optical power for a GaAs tip and semitransparent Au sample. The solid curve is a logarithmic fit to the photovoltage and the setpoint value for $I_{0}$ is $V=0, I=50 \mathrm{pA}$.

$\mathrm{mV}$. We note here the presence of a small contribution to $I_{0}$. which does not change significantly upon a variation of tipsample separation. In this regime of operation, the internal transport mechanisms are the principal current limiting factors for negative sample bias. Figure 2(c) shows the characteristics with $12 \mu \mathrm{W}$ of photoexcitation producing a $V_{p}$ of about $450 \mathrm{mV}$. The rectifying behavior is suppressed, and $I_{0}$ is limited by the tip-sample separation, reaching values over $500 \mathrm{pA}$. Clearly the tunnel current must derive from a volume in the tip, centered near the tunnel junction.

To further characterize the tip response we have measured both $V_{p}$ and $I_{0}$ as a function of light intensity. Figure 3 shows our results for $V_{p}$ (filled circles) at the apex of a GaAs $\left(n-10^{17} \mathrm{~cm}^{-3}\right)$ tip, again using the Au thin film. The logarithmic fit (solid) to these data is indicative of the current transport mechanisms outlined earlier, and is addressed in a more detailed study of tip photoresponse. ${ }^{12}$ The important point here is despite the unknown structure, composition, and electronic properties of the tip surface, the bulk excitation and transport still render a well-defined tip potential. The data labeled a, b, c, and d are measurements of $I_{0}$ as the light intensity is ramped during which the tunnel current regulation is disabled. Each curve represents a different tipsample separation. For the largest separation (curve a), the current displays a saturating behavior with light intensity which becomes less pronounced as the tip is brought closer to the surface (b, c, and d). This may be explained qualitatively in terms of photoexcitation acting as a local current source in series with the tunnel impedance. When the impedance is high (curve a) the tip effectively behaves as a voltage source. As the tunnel impedance is lowered, the tip behaves more like a current source, with $I_{0}$ nearly proportional to the excitation intensity. It is particularly interesting to estimate the effective collection volume from the tip responsivity at low excitation levels. The slope of curve (d) is $\approx 10^{-2}$ $\mathrm{nA} / \mathrm{nW}$ corrected for $25 \%$ transmission of the thin film substrate. If the conversion efficiency was $100 \%$, then the mini- 


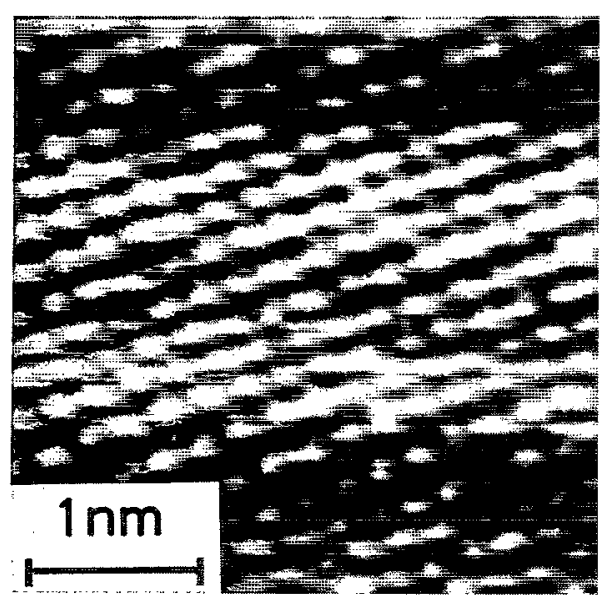

FIG. 4. STM image of a graphite surface using Si tip with $1 \mathrm{~mW}$ laser excitation at zero applied voltage. The tunnel current is $50 \mathrm{pA}$.

mum collection radius would be about $1.1 \mu \mathrm{m}$, which is roughly comparable to the minority carrier diffusion length in GaAs. ${ }^{13}$ The process of charge generation, diffusion, drift, and finally tunneling appears to be surprisingly efficient within a small region near the tip apex.

The measurements shown here support the notion of a photosensitive scanned probe using semiconductors whose minority carrier transport lengths could ultimately determine the probe photoresponse. ${ }^{12}$ To illustrate the stability of the photovoltage at the tip apex, Fig. 4 shows a STM topograph of a graphite surface made with a Si tip at zero applied bias where now the potential is generated by laser excitation.

Considering the variety of scanned probe microscopies exploiting the local optical interactions, the prospect of a convenient, stable, and sensitive optical probe is welcome. In this letter we demonstrated the sensitivity of semiconductor STM tips to an incident optical field, showing they are not too different from their macroscopic counterparts. The tip photovoltage is similar in many respects to the surface photovoltage previously measured by STM potentiometry and furthermore the STM junction may be adjustcd to yield either photovoltaic or photoamperic behavior.

We would like to thank J. Hermsen, J. Gerritsen, and A. F. van Etteger for their superb technical support. Part of this work was supported by the Stichting Fundamenteel Onderzoek der Materie (FOM), which is financially supported by the Nederlandse Organisatie voor Wentenschappelijk Onderzoek (NWO).

${ }^{1}$ M. H. Hecht, J. Vac. Sci. Technol. B 8, 1018 (1990).

${ }^{2}$ R. J. Hamers and K. Markert, Phys. Rev. Lett. 64, 1051 (1990).

${ }^{3}$ Y. Kuk, R. S. Becker, P. J. Silverman, and G. P. Kochanski, Phys. Rev. Lett. 65, 456 (1990).

${ }^{4}$ G. F. A. van de Walle, H. van Kempen, and P. Wyder, Surf. Sci. 181, 356 (1987).

${ }^{5}$ O. J. Glembocki, E. S. Snow, C. R. K. Marrian, S. M. Prokes, and D. S. Katzer, Ultramicroscopy 42, 764 (1992).

${ }^{6} \mathrm{~S}$. Akari, M. Ch. Lux-Steiner, M. Vögt, M. Stachel, and K. Dransfeld, J. Vac. Sci. Technol. B 9, 561 (1991).

${ }^{7}$ D. G. Cahill and R. I. Hamers, J. Vac. Sci. Technol. B 9, 564 (1991).

${ }^{8}$ M. McEllistrem, G. Haase, D. Chen, and R. J. Hamers, Phys. Rev. Lett. 70, 2471 (1993).

${ }^{9}$ C. M. Aldao, A. Palermo, and J. H. Weaver, J. Vac. Sci. Technol. A 10, 493 (1992).

${ }^{10}$ L. Q. Qian and B. W. Wessels, Appl. Phys. Lett. 58, 1295 (1991).

${ }^{11}$ R. Jansen, M. C. M. M. van der Wielen, M. W. J. Prins, D. L. Abraham, and H. van Kempen, J. Vac. Sci. Technol. (to be published).

${ }^{12}$ M. W. J. Prins, M. C. M. M. van der Wielen, R. Jansen, D. L. Abraham, and $\mathrm{H}$. van Kempen (unpublished).

${ }^{13}$ M. S. Sze, Physics of Semiconductor Devices (Wiley, New York, 1981). 